\title{
Cerebellar degeneration in dominantly inherited spastic paraplegia
}

\author{
CL SCHOLTZ, M SWASH \\ From the Departments of Neuropathology and Neurology, The London Hospital and The London Hospital \\ Medical College, London, UK
}

SUMMARY The clinical features of five affected members in three generations of a family with dominantly inherited Strumpell's spastic paraplegia are described, together with the pathological findings in two cases. The late presentation and slow progression of the disease encompass features of the types I and II of other authors illustrating the heterogeneous expression of the disorder. Cerebellar involvement was evident clinically and pathologically.

Hereditary spastic paraplegia is a disorder characterised by slowly increasing spasticity and weakness of the lower limbs.' Since Seeligmuller's original study ${ }^{2}$ and the reports of Strumpell ${ }^{34}$ and Lorrain ${ }^{5}$ approximately 200 families with the disorder have been described. ${ }^{6-11}$ Pathologically it is characterised by degeneration of the corticospinal tracts and, to a lesser extent, of the posterior columns. ${ }^{167}$ It may present as a pure form, "Strumpell-Lorrain Disease", ${ }^{3-578}$ in which degeneration of the corticospinal tracts occurs below the decussation of the pyramids, ${ }^{7}$ or as a complicated form in which there is extension of the disease process into other neuronal systems. ${ }^{8}$ In the latter, optic nerve involvement and retinal degeneration have been described and extrapyramidal features, distal atrophy of the upper limbs, and dementia may also occur. ${ }^{9}$ Mild cerebellar ataxia may occur in the arms in some cases, but ataxia of gait is uncommon. ${ }^{10}$ Hereditary spastic paraplegia is of adult onset and progression is slow; longevity is usually unimpaired.

Two forms of pure dominantly inherited spastic paraplegia have been recognised..$^{78}$ In the Type 1 form, spasticity of the lower limbs is more marked than weakness. In this group of patients there is usually a history of delay in developmental milestones, particularly in walking, and the disorder usually presents before the age of 35 years. Progression is slow and disability variable. In the Type 2 form muscle weakness, distal sensory loss and urinary urgency or even incontinence may be evident. This form usually

Address for reprint requests: Dr M Swash, The London Hospital, Whitechapel, London E1 1BB, UK.

Received 3 April 1984 and in revised form 19 July 1984.

Accepted 21 July 1984 presents after the age of 35 years but progresses more rapidly resulting in more disability than in the Type 1 form. Families affected by a similar disorder, but inherited as an autosomal recessive trait have also been reported, but this mode of inheritance is uncommon. ${ }^{811}$ Many of these latter families show other features, in addition to corticospinal tract involvement. $^{8}$

In this report we describe the clinical and pathological features of . a late-onset, dominantly inherited form of the disease in which ataxia accompanied severe spastic paraplegia.

\section{Clinical features}

The family tree is illustrated in fig 1.

Generation II (six members; one affected)

II.1. female, II.2. female, II.3. female. Died in infancy cause unknown.

II.4. female. Died aged 83 yr. She was bedridden for many years before her death. Postmortem examination carried out 40 years ago at another hospital showed degeneration of the lateral columns and spinocerebellar tracts. No further details are known:

II.5. female. Died in childhood.

II.6. male. Died aged 36 yr of pulmonary tuberculosis.

Generation III (six members; two affected)

III.1. female. Died aged $60 \mathrm{yr}$ of pneumonia and renal disease.

III.2. female. Presented aged $50 \mathrm{yr}$ with gradually progressive spastic paraplegia. She required a wheelchair by the age of about 70 years. No cerebellar ataxia was observed in the arms. Eye movements and vision were normal. She died at the age of 84 years. Postmortem examination was performed.

III.3. female. Died aged $5 \mathrm{yr}$ of meningitis. 


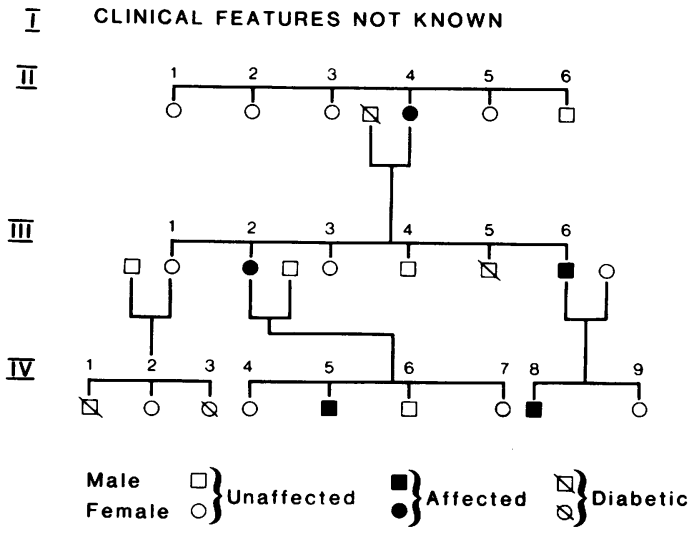

Fig 1 Genealogical table of family.

III.4. male. Died aged $2 \mathrm{yr}$ of meningitis.

III.5. male. Died aged 11 yr of diabetes mellitus.

III.6. male. Died aged 76 yr. In the 5th decade he complained of unsteadiness of gait and weakness, and this progressed slowly. He was completely disabled by the age of $63 \mathrm{yr}$ and died suddenly of myocardial infarction. Postmortem examination was not carried out.
Generation IV (nine members; two affected)

In this generation no neurological disease has developed in the offspring of Case III.1, but two have diabetes mellitus. IV.1. male. Died aged 70 yr of diabetes mellitus.

IV.2. female. Died aged $51 \mathrm{yr}$ of myocardial infarction.

IV.3. female. Died aged 63 yr of diabetes mellitus.

There are four offspring of case III.2. of whom one has neurological disease.

IV.4. female. Died aged 71 yr. No neurological symptoms.

IV.5. male. Now aged $69 \mathrm{yr}$. This patient, a physician, presented at the age of $47 \mathrm{yr}$ because he was less coordinated and because he noted that his toes were catching on the ground. Examination showed little abnormality at this time but in the next ten years he slowly developed cerebellar ataxia in the legs, and to a lesser extent in the arms, accompanied by extensor plantar responses, mild spasticity, and increased reflexes in the legs. Strength in the legs was normal and sensation was intact. At the age of $59 \mathrm{yr}$ there was mild cerebellar ataxia in the arms but in the legs there was marked spasticity with ataxia of gait, without weakness; the knee jerks were present and the plantar responses were extensor. Slight urgency of defaecation and micturition with occasional incontinence of urine were noted. There was distal sensory impairment in the legs, and the ankle jerks were absent. The fundi were normal. The glucose tolerance test was normal. Although the disorder has slowly progressed his disability has remained moderate and he is mobile with a walking frame. There is no intellectual impairment.

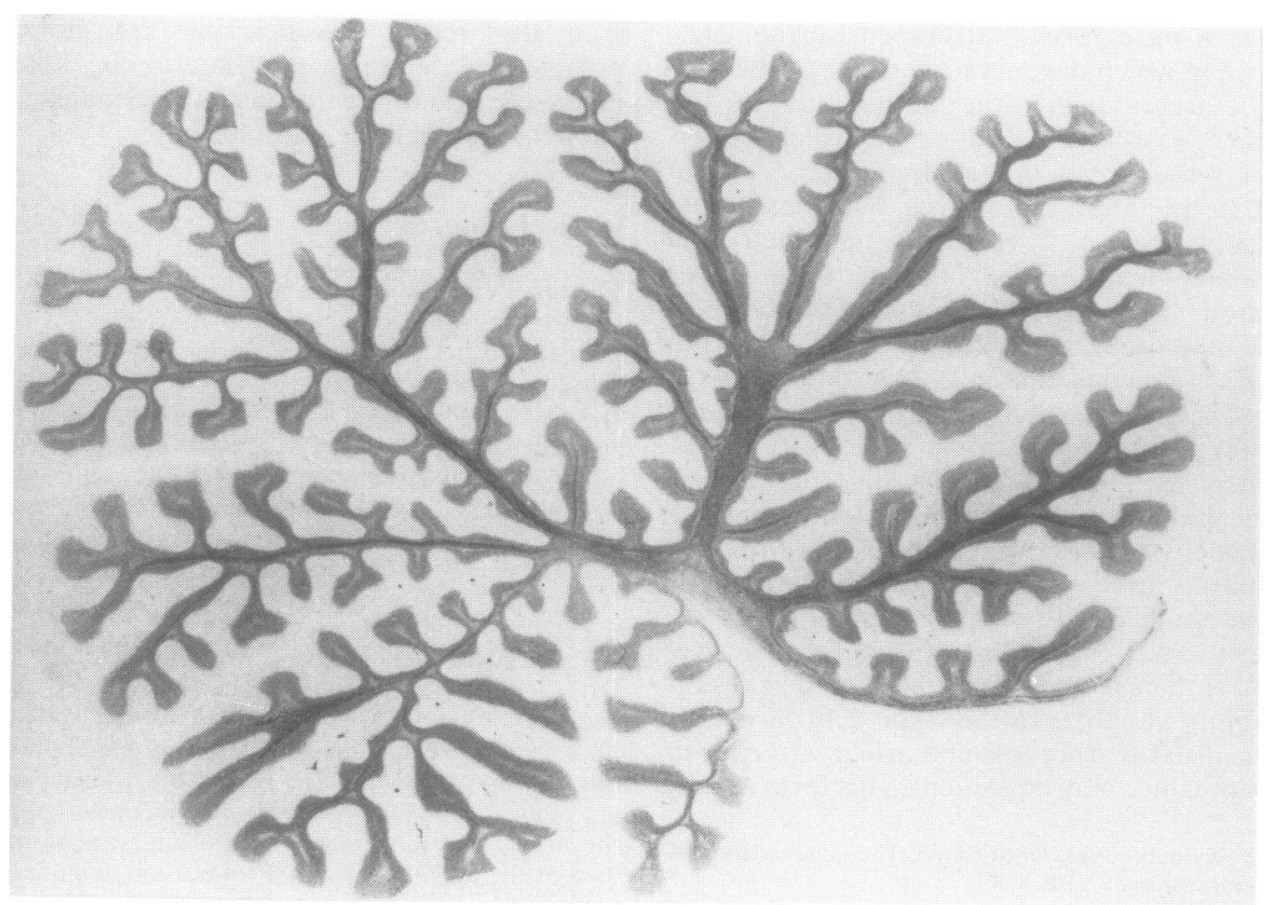

Fig 2 Cerebellum. There is atrophy of the folia (Luxol Fast Blue $\times 3$ ). 


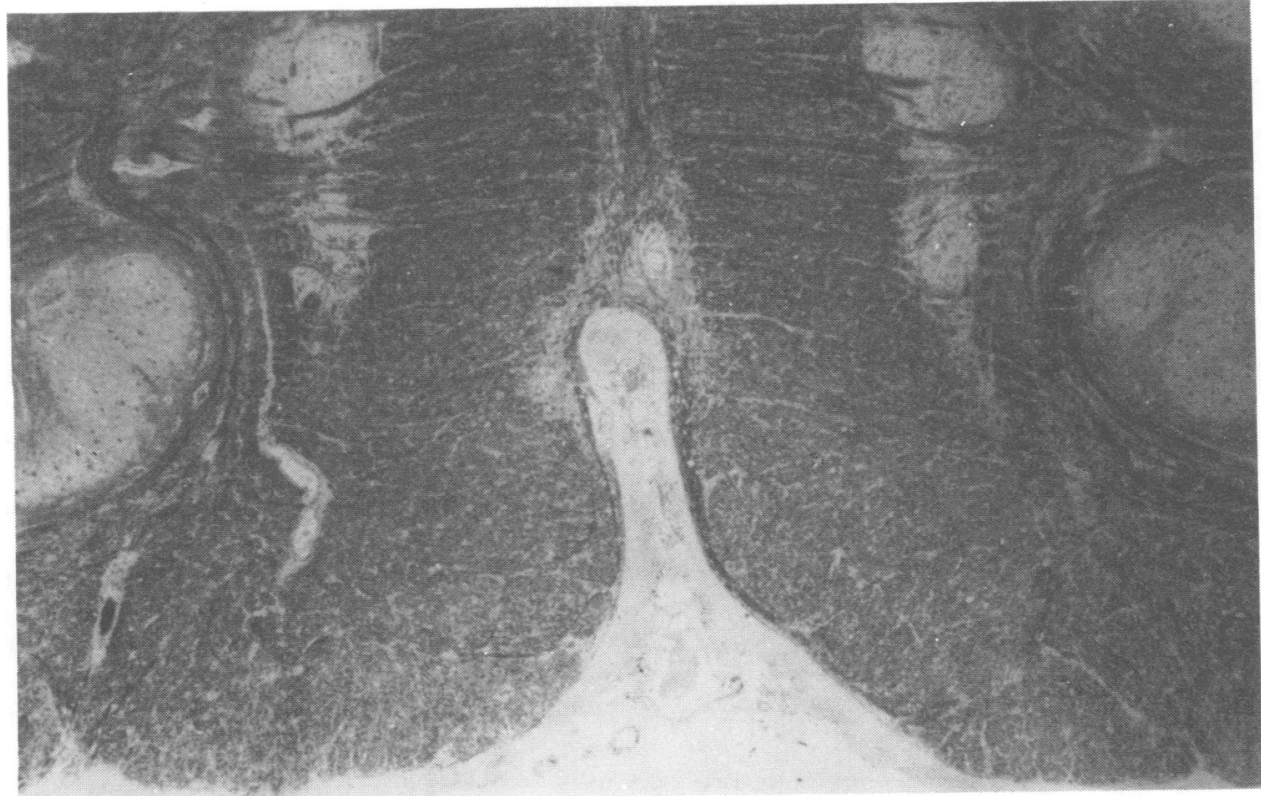

Fig 3 Medulla. Demyelination of the pyramids (Luxol Fast Blue $\times 25$ ).

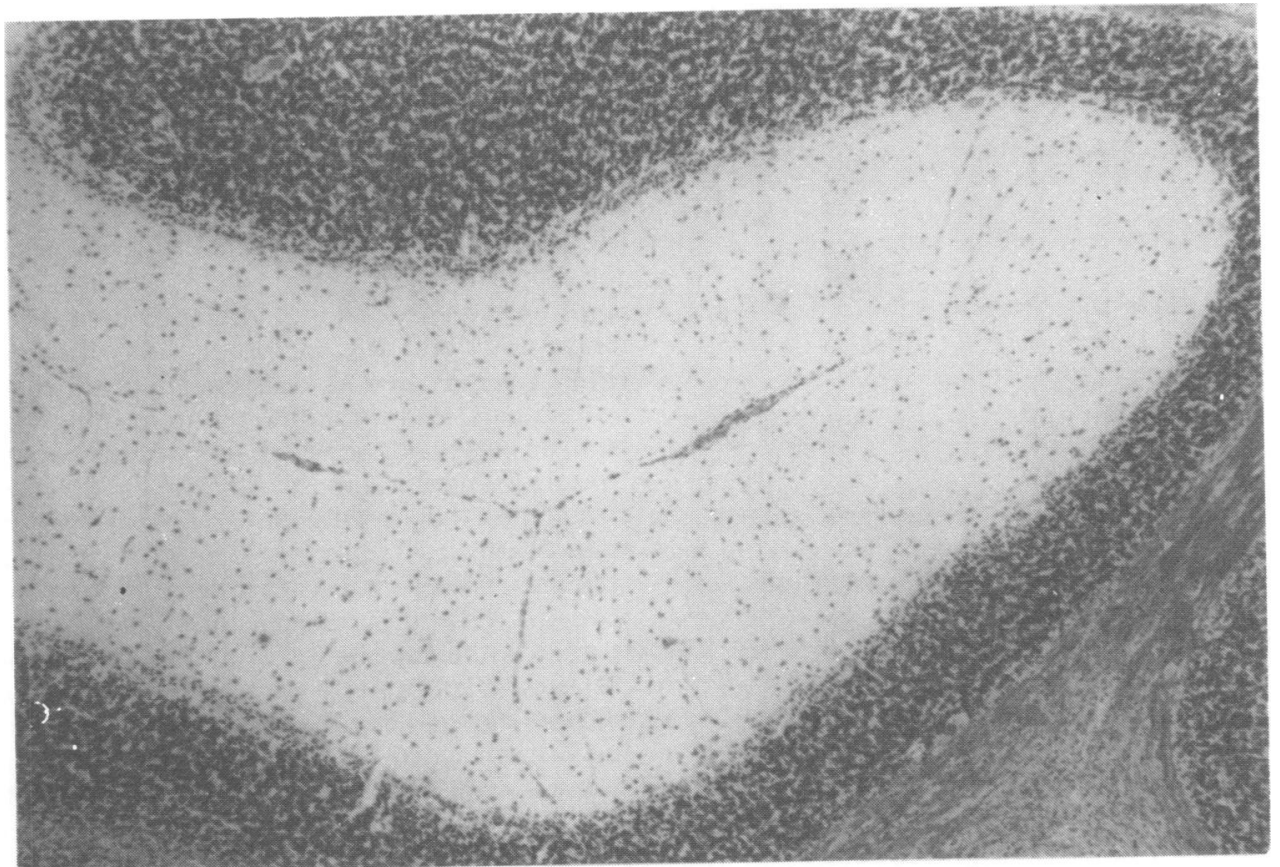

Fig 4 Cerebellar cortex. There is almost total loss of Purkinje neurons (Luxol Fast Blue $\times 80$ ). 


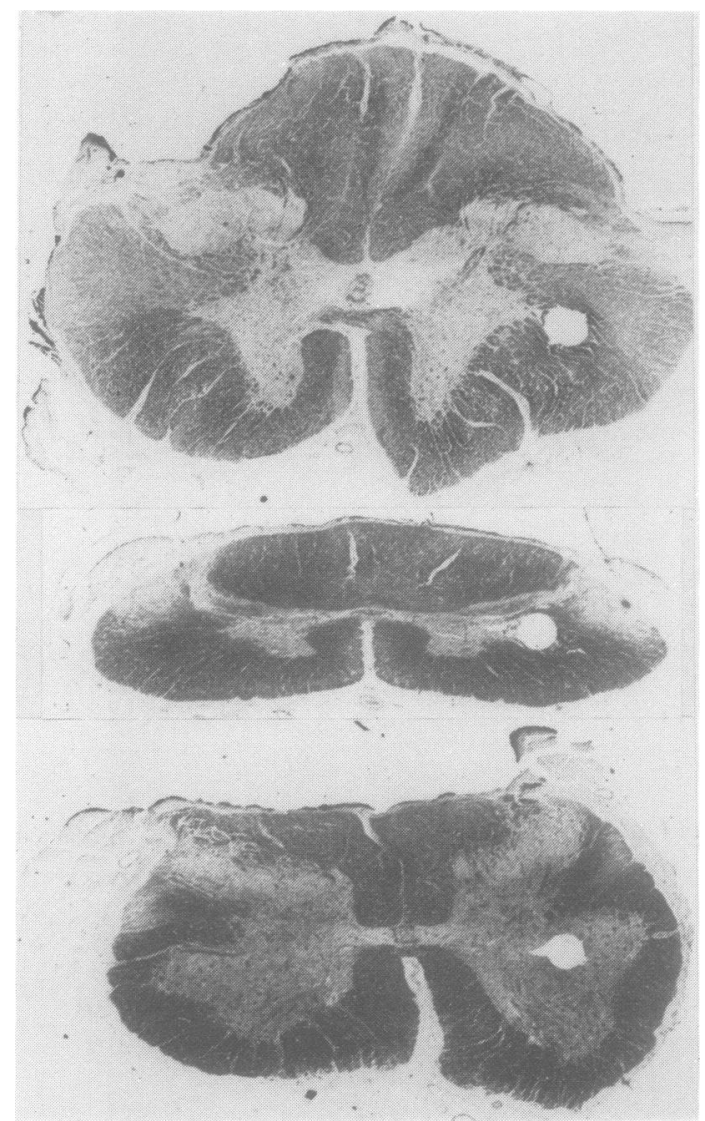

Fig 5 Spinal cord. TS (a) C3, (b) T9 and (c) L4. The demyelination and axonal loss in the corticospinal and spinocerebellar tracts is most marked at the thoracic level (b) while that of the posterior columns is most evident at the cervical level (a) (Luxol Fast Blue $\times 6$ ).

IV.6. male. Stillborn. Rhesus incompatibility.

IV.7. female. Stillborn. Rhesus incompatibility.

There are two offspring of III.6, one with neurological symptoms.

IV.8. male. Aged 53 yr. This man developed unsteadiness of gait at the age of $44 \mathrm{yr}$. Examination revealed mild symmetrical cerebellar ataxia in the upper and lower limbs: in the legs there was mild spasticity without weakness. Both plantar responses were extensor. There were no sphincter or sensory disturbances. Vision and ocular movements were normal.

IV.9. female. Has recently suffered from leg cramps.

Generation $I V$ (thirteen members)

No neurological disturbance is apparent in this generation of the family. The oldest member is as yet only 43 years old.

\section{Pathology}

Case 11.4. showed degeneration of the lateral columns and spinocerebellar tracts. No further details are known.

Case III.2. The cerebral hemispheres appeared normal. The cerebellum was generally shrunken (fig 2) but there was no focal abnormality. The cranial nerves were normal and the cerebral vessels were patent. The spinal cord was atrophic, particularly in the thoracic region. Microscopic examination showed no abnormality in the cerebral hemispheres. In the medulla there was severe axonal degeneration and demyelination of the pyramids (fig 3). In the cerebellum the Purkinje neurons were virtually absent and the granular layer was thin (fig 4). The dentate nucleus was normal. In the spinal cord there was severe axonal degeneration and demyelination of the dorsal spinocerebellar tracts, and of the crossed and uncrossed corticospinal tracts (fig 5). These changes were particularly marked in the thoracic and cervical cord. The gracile and cuneate columns were also affected, but to a lesser degree. Clarke's column was normal. There was no loss of anterior horn cells. The dorsal root ganglia were not examined.

\section{Discussion}

Spastic paraplegia, accompanied by cerebellar fea tures, occurred in five members of this family. IT each case the disease presented in the fifth decade. If was characterised by spasticity and then by weak? ness in the legs but progression of the disability was slow and there was no reduction of life expectancy. Distal sensory loss and sphincter impairment developed, to a relatively minor degree, in one case. Necropsy of two cases showed the typical degeneration of the corticospinal and spinocerebellar pathways described in previous reports. Diabetes mellitus was inherited as a genetically distinct trait.

Families with dominantly inherited hereditary spastic paraplegia in which the symptoms are of late onset, as in this family, have been described less frequently than those with early onset. Typically, the age of onset is relatively constant within affected families. ${ }^{12}$ The clinical features noted in this family overlap those described in the Type 1 and Type 2 form of the disease as characterised in previous reports. ${ }^{78}$ The late age of onset is consistent with the Type 2 disorder but the benign nature of the illness, and the absence of sensory symptoms, with minor urinary symptoms, fit better with the Type 1 disorder. This divergence of symptoms is consistent with the genetic heterogeneity expected in this autosomal dominant disorder. ${ }^{13}$ Most patients present with 
spastic paraplegia alone, but pathological studies have shown involvement of the posterior columns and of the ascending spinocerebellar pathways. In the Type 2 form of familial spastic paraplegia, ataxia of gait may be present often in association with slight distal sensory impairment, but pure cerebellar ataxia of gait appears to be very uncommon. ${ }^{14}$ Indeed, most reports do not comment on the presence or absence of cerebellar signs, or of the histological features in the cerebellum. It is conceivable that this absence of reports of cerebellar involvement reflects the overwhelming predominance of the spastic paraplegia. In this Type 2 form, however, the degeneration may extend into other neuronal groups.

In our case III.2. necropsy showed a virtually complete loss of cerebellar Purkinje cells. The number of Purkinje cells decreases with advancing age so that in the ninth decade about $75 \%$ of these cells remain; ${ }^{16}$ the changes in Case III. 2 could not thus be explained by ageing. The dentate nucleus was spared. In the spinal cord there was degeneration not only of the corticospinal tracts but also of spinocerebellar tracts and posterior columns. This patient's son (case IV.5) also has mild cerebellar ataxia in addition to spastic paraplegia.

Greenfield ${ }^{17}$ classified dominantly inherited spastic paraplegia with the hereditary spinocerebellar degenerations. He argued that several dominantly inherited examples of the latter, described as hereditary spastic ataxia were shown at necropsy to have lesions involving the spinal cord. In the Schut-Haymaker family, ${ }^{18}$ for example the disease differentiated in the third generation into several types, resembling respectively Friedreich's ataxia, hereditary cerebellar ataxia and hereditary spastic paraplegia with minimal ataxia. Similarly in the Menzel form of hereditary cerebellar ataxia ${ }^{19}$ there is spinal cord degeneration, resembling that found in our cases, with cerebellar degeneration, and atrophy of the olives and of the pons.

We thank Case IV.5, a physician, who recognised the unusual nature of his familial disorder, and Dr Charles Simpson of Vancouver, Canada and Dr Ronald Henson, London, for providing us with details of the clinical features.
References

1 Schwartz GA. Hereditary (familial) spastic Paraplegia. Arch Neurol Psychiat 1952;68:655-82.

${ }^{2}$ Seeligmuller A. Skelerose der seitenstrange des Ruckenmarks bei 4 Kindern derselben Familie, Deutsche Med. Wochnschr 1876;2:185-6.

${ }^{3}$ Strumpell A. Beitrage zur Pathologie des Ruckenmarks, Arch Psychiat Nervenkr 1880;10:676-717.

${ }^{4}$ Strumpell A. Die primare Seitenstrangsklerose (Spastische Spinalparalyse) Deutsch Nervenheilkunde 1904;27:291-339.

${ }^{5}$ Lorrain M. Contribution a l'etude de la Paraplegie Spasmodique Familiale. Paris. G Steinheil 1898.

- Schwartz GA, Liu C-N. Hereditary (familial) spastic paraplegia. Arch Neurol 1965;75:144-62.

${ }^{7}$ Behan WMH, Maia M. Strumpell's familial spastic paraplegia: genetics and neuropathology. $J$ Neurol Neurosurg Psychiatry 1974;37:8-20.

${ }^{8}$ Harding AE. Hereditary "pure" spastic paraplegia: a clinical and genetic study of 22 families. $J$ Neurol Neurosurg Psychiatry 1981;44:871-83.

${ }^{9}$ Price GE. Familial lateral sclerosis (spastic paralysis). $J$ Nerv Ment Dis 1939;90:51-3.

${ }^{10}$ Skre H. Hereditary spastic paraplegia in Western Norway. Clin Genet 1974; 6: 165-83.

"Harding AE. Classification of the hereditary ataxias and paraplegias. Lancet 1983; ii: 1151-5.

12 Holmes GL, Shaywitz BA. Strumpell's pure familial spastic paraplegia: case study and review of the literature. J Neurol Neurosurg Psychiatry 1977;40:1003-8.

${ }^{13}$ Harris H, Smith CAB. The sib-sib age of onset correlation among individuals suffering from a hereditary syndrome produced by more than one gene. Ann Eugenics 1947/9;14:309-18.

14 Landau WM, Gitt JJ. Hereditary spastic paraplegia and hereditary ataxia: a family demonstrating a variety of phenotypic manifestations. Arch Neurol Psychiat 1951;66:346-54.

${ }^{15}$ Schmit RW. Hereditary ataxia; a clinical study through six generations. Arch Neurol Psychiat 1950;63:53568.

${ }^{16}$ Corsellis JAN. Some observations on the Purkinje cells population and on brain volume in human ageing. In: Neurobiology of Aging Vol 3. Terry D, Gershon S. eds. Raven Press New York 1976:205.

17 Greenfield JG. The Spino-Cerebellar Degenerations. Oxford Blackwell.

${ }^{18}$ Schut JW, Haymaker W. Hereditary ataxia: pathologic study of five cases of common ancestry. $J$ Neuropath Clin Neurol 1951;1:189-213.

${ }^{19}$ Menzel P. Beitrage zur kenntnis der hereditaren ataxie und Kleinhirnatrophie. Arch Psychiat u Nervenkr, 1891:22: 160 . 